\title{
Long-term survival trends of gastric cancer patients between 1972 and 2011 in Qidong
}

\author{
Yong-Sheng Chen ${ }^{1}$, Jian-Guo Chen ${ }^{1,2^{*}}$, Jian Zhu' ${ }^{1}$ Yong-Hui Zhang ${ }^{1}$ and Lu-Lu Ding ${ }^{1}$
}

\begin{abstract}
Background: There have been few reports on long-term survival of gastric cancer patients. This study analyzed the survival data of gastric cancer patients obtained from the population-based Qidong Cancer Registry between 1972 and 2011, providing a basis for evaluation of gastric cancer treatment and prognosis.

Methods: The cumulative observed survival rate and relative survival rate of gastric cancer patients were calculated using Hakulinen's method via the SURV3.01 software, which was developed by the Finnish Cancer Registry. The date of the last follow-up for the survival status of the 15,401 registered cases was April 30, 2012.

Results: The 1-, 5-, 10-, 20-, and 30-year observed survival rates were $33.82 \%, 14.18 \%, 10.35 \%, 6.63 \%$, and $4.19 \%$, respectively, and the 1-, 5-, 10-, 20-, and 30-year relative survival rates were $35.43 \%, 18.13 \%, 17.50 \%, 21.96 \%$, and $32.84 \%$, respectively. For males, the corresponding observed survival rates were $34.50 \%, 14.40 \%, 10.42 \%, 6.46 \%$, and $4.05 \%$, and the corresponding relative survival rates were $36.23 \%, 18.67 \%, 18.28 \%, 23.73 \%$, and $38.61 \%$. For females, the corresponding observed survival rates were $32.62 \%, 13.80 \%, 10.22 \%, 6.95 \%$, and $4.46 \%$, and the corresponding relative survival rates were $34.03 \%, 17.21 \%, 16.28 \%, 19.70 \%$, and $26.78 \%$. Significant differences in relative survival rates were observed between sexes $(P=0.003)$. For the 15-34, 35-44, 45-54, 55-64, 65-74, and 75+ age groups, the 5-year relative survival rates were $16.13 \%, 21.77 \%, 18.63 \%, 12.61 \%, 7.99 \%$, and $2.94 \%$, respectively, and the 10 -year relative survival rates were $16.49 \%, 22.83 \%, 20.50 \%, 15.97 \%, 15.88 \%$, and $15.73 \%$, respectively. Remarkable improvement could be observed for the 5-, 10-, and 15-year relative survival rates in Qidong beginning in the 1980s.
\end{abstract}

Conclusion: The survival outcome of registered gastric cancer cases in Qidong showed gradual progress over the past two decades.

Keywords: Gastric neoplasms, Cancer registration, Survival, Trends, Qidong

\section{Background}

Gastric cancer is the fifth most common malignancy in the world according to statistics from GLOBOCAN 2012, with nearly one million new cases per year (952,000 cases, $6.8 \%$ of the total) [1]. More than $70 \%$ of cases $(677,000$ cases, with 456,000 in males and 221,000 in females) occur in developing countries, and half of the world total occurs in East Asia (mainly in China).

\footnotetext{
*Correspondence: chenjg@vip.sina.com

1 Qidong Liver Cancer Institute, Qidong People's Hospital, Qidong, Jiangsu 226200, P.R. China

Full list of author information is available at the end of the article
}

In the Western Pacific Region, the stomach is the second leading cancer site in males and the fourth most common cancer site in females [2]. In mainland China, gastric cancer is the third most common malignant disease, which makes it a main disease burden among Chinese residents. In 2009, the age-standardized rate (ASR) of incidence adjusted by Chinese population (ASRIC) for gastric cancer was 17.85 per 100,000 (25.37 per 100,000 in males and 10.62 per 100,000 in females) [3]. The ASR of incidence adjusted by world population (ASRIW) was 22.7 per 100,000 (32.8 per 100,000 in males and 13.1 per 100,000 in females) [1]. In Qidong, gastric cancer has been the second most common cancer over the past 
40 years, with a crude incidence of 34.26 per 100,000 and an ASRIW of 25.59 per 100,000 , accounting for $16.60 \%$ of all cancer cases. The annual percentage change (APC) in the ASRIW has been $-2.06 \%$, with an accelerating decline between 1972 and 2011 [4].

To date, gastric cancer is usually detected late, hence patient survival rates are poor in most settings [5]. Reports on long-term survival of gastric cancer patients are rare. The prognosis of neoplasms has been shown to be poor in China [6], so the 1-year survival rate is used to reflect patients' short-term living status, whereas the 5 -year survival rate is generally used as an indicator of patients' long-term living status. The relative survival rate calculated from population-based cancer registry data, which is based on the concept of the probability of survival at the same age, with the same sex, and in the same period, is a helpful metric to compare the prognoses of patients from different areas $[7,8]$.

Recently, to develop effective public health policies for cancer control, China has made efforts to improve its systematic recording of cancer data and to report the survival rates for different cancers, including gastric cancer, adjusted by age, sex, and locality [6]. However, these efforts provide only a very short interval (2003-2005) for evaluating the survival of patients with gastric cancer in only limited areas. To better understand the effects of changes or improvement in the outcomes of gastric cancer diagnosis and treatment in a sentinel rural population and to provide valuable insights for future planning of preventative activities by health authorities, this study analyzed the survival rates of gastric cancer patients from a population-based cancer registry in Qidong over the period of 1972-2011. Qidong is located at the mouth of the Yangtze River, to the north of Shanghai. Qidong is a city (former county) in Jiangsu Province, covering an area of $1234 \mathrm{~km}^{2}$ and containing a registered resident population of 1.12 million as of the end of 2013.

The Qidong Cancer Registry was designated as a cancer registration repository by the local health authority in 1972, with compulsory reporting by health care workers. Several years later, cancer registration was mandated to be compulsory by the provincial health authority. This cancer registry is now a member of the national monitoring program (known as the National Cancer Registration Network) $[9,10]$ of the National Central Cancer Registries of China, supported by the Ministry of Finance and the Ministry of Health of China: Tumor Follow-up Registration Programs (MF2008-293, 2009-193, and 2010-90).

\section{Methods}

\section{Data collection}

The Qidong Cancer Registry uses both active and passive methods for cancer data collection. As a member of the International Association of Cancer Registries, the Qidong Cancer Registry implemented the association's standards for quality, completeness, timeliness, and unresolved duplicate records. The International Classification of Diseases, 10th revision (ICD-10), is used for cancer classification; gastric cancer is coded as C16. All data files received from lower-level registries and all other hospitals are compared with cancer report lists and death certification notifications (DCNs) to track down missing cases and to exclude duplicate registrations. When the registry personnel receive the death notification first, the patient's medical records are reviewed, or a home visit is carried out to obtain further information. Those patients without any death information would be presumed to be still alive ("survivors"), and active follow-up is conducted as a routine procedure [9]. In addition, periodic followup is performed every 5 years. The deadline for the latest follow-up for the data set studied here was April 30, 2012.

\section{Quality control of data}

The percentage of morphologic verification (MV\%), the ratio of mortality to incidence $(\mathrm{M} / \mathrm{I})$, and the percentage of death certificate only cases (DCO\%) were used as indices of quality control. The DCN data from the Qidong All-Death-Cause Registration System [9] were linked to and compared with new registered cases if the patient had died. The survival of each case was determined as the duration from the date of initial diagnosis to the date of death due to gastric cancer, the date of death due to other diseases, the date of last follow-up, or the date of closing for those who were still alive. The Qidong Cancer Registry data had been included in "Cancer Incidence in Five Continents" (CI5) $[1,11,12]$ and other publications [9, 10]. The reliability of these data had earned recognition in both domestic and international studies [9-12].

\section{Statistical methods}

The cumulative observed survival rate and relative survival rate were computed for six age groups (15-34, 35-44, 45-54, 55-64, 65-74, and 75+) and nine calendar periods (1972, 1973-1977, 1978-1982, 1983-1987, 1988-1992, 1993-1997, 1998-2002, 2003-2007, and 2008-2011). The observed survival and relative survival rates were calculated by using the SURV3.01 software developed by Hakulinen from the Finnish Cancer Registry [13]. The relative survival rate was calculated by dividing the observed survival rate by the expected survival rate for a group of people in the general population who are similar to the patient group with respect to sex, age, and the calendar period of observation [14], i.e., $S_{c}(t)=S_{o}(t) / S_{e}(t)$, where $S_{c}(t)$ is the relative survival rate, $S_{o}(t)$ is the observed survival rate, and $S_{e}(t)$ is the expected survival rate, and $S_{e}(t)=\sum n_{x} S_{e x}(t) / \sum n_{x}$, where 
$n_{x}$ is the number of patients being followed up at the age of $x$ and $S_{e x}(t)$ is the survival rate at the time point $t$ at the age of $x$. The expected survival rate for a group of people in the general population who are similar to the patient group with respect to sex, age, and the registered calendar year of observation was calculated using the Qidong life tables [7, 15] for the years 1974-2011.

\section{Results}

\section{Quality-control indices}

There were 15,401 cases of gastric cancer from 1972 to 2011, among which 9804 were males and 5597 were females (the ratio of males to females was 1.75:1). The MV\% was $55.52 \%$, the M/I ratio was 89.49 , and the DCO \% was $0.19 \%$. The number of deaths due to gastric cancer was 13,675 (88.79\%), and the number of deaths due to other diseases was four (0.03\%). A total of 452 (2.93\%) patients were lost to follow-up, and 1270 (8.25\%) were still alive by the end of 2011 .

\section{Observed survival and relative survival of gastric cancer patients}

The 1-, 3-, 5-, 10-, 15-, 20-, and 30-year observed survival rates were $33.82 \%, 17.97 \%, 14.18 \%, 10.35 \%, 8.29 \%$, $6.63 \%$, and $4.19 \%$, respectively, and the 1-, 3-, 5-, 10-, $15-, 20-$, and 30 -year relative survival rates were $35.43 \%$, $20.74 \%, 18.13 \%, 17.50 \%, 19.27 \%, 21.96 \%$, and $32.84 \%$, respectively. The observed survival and relative survival rates by year and their standard errors (SEs) are depicted in Fig. 1a.

\section{Survival rate by sex}

The 1-, 3-, 5-, 10-, 15-, 20-, and 30-year observed survival rates were $34.50 \%, 18.46 \%, 14.40 \%, 10.42 \%, 8.24 \%$, $6.46 \%$, and $4.05 \%$, respectively, for male patients, and were $32.62 \%, 17.11 \%, 13.80 \%, 10.22 \%, 8.40 \%, 6.95 \%$, and $4.46 \%$, respectively, for female patients, with no significant differences between males and females. The 1-, 3-, 5-, 10-, 15-, 20-, and 30-year relative survival rates were $36.23 \%, 21.48 \%, 18.67 \%, 18.28 \%, 20.47 \%, 23.73 \%$, and $38.61 \%$, respectively, for male patients, and were $34.03 \%$, $19.47 \%, 17.21 \%, 16.28 \%, 17.56 \%, 19.70 \%$, and $26.78 \%$, respectively, for female patients, with significant differences between males and females $\left(x^{2}=24.79, P=0.003\right)$. The results of the observed survival and relative survival rates by sex are shown in Fig. 1b.

\section{Survival rate by age}

Significant differences in relative survival rates were found among the age groups of 15 years and over both for males $\left(X^{2}=440.72, P<0.001\right)$ and for females $\left(X^{2}=426.16, P<0.001\right)$. The highest 5 -year observed survival and relative survival rates were seen in the age group of 35-44, and the highest 10-year observed survival and relative survival rates were seen in the age groups of $45-54$ and $35-44$, respectively. The patients in

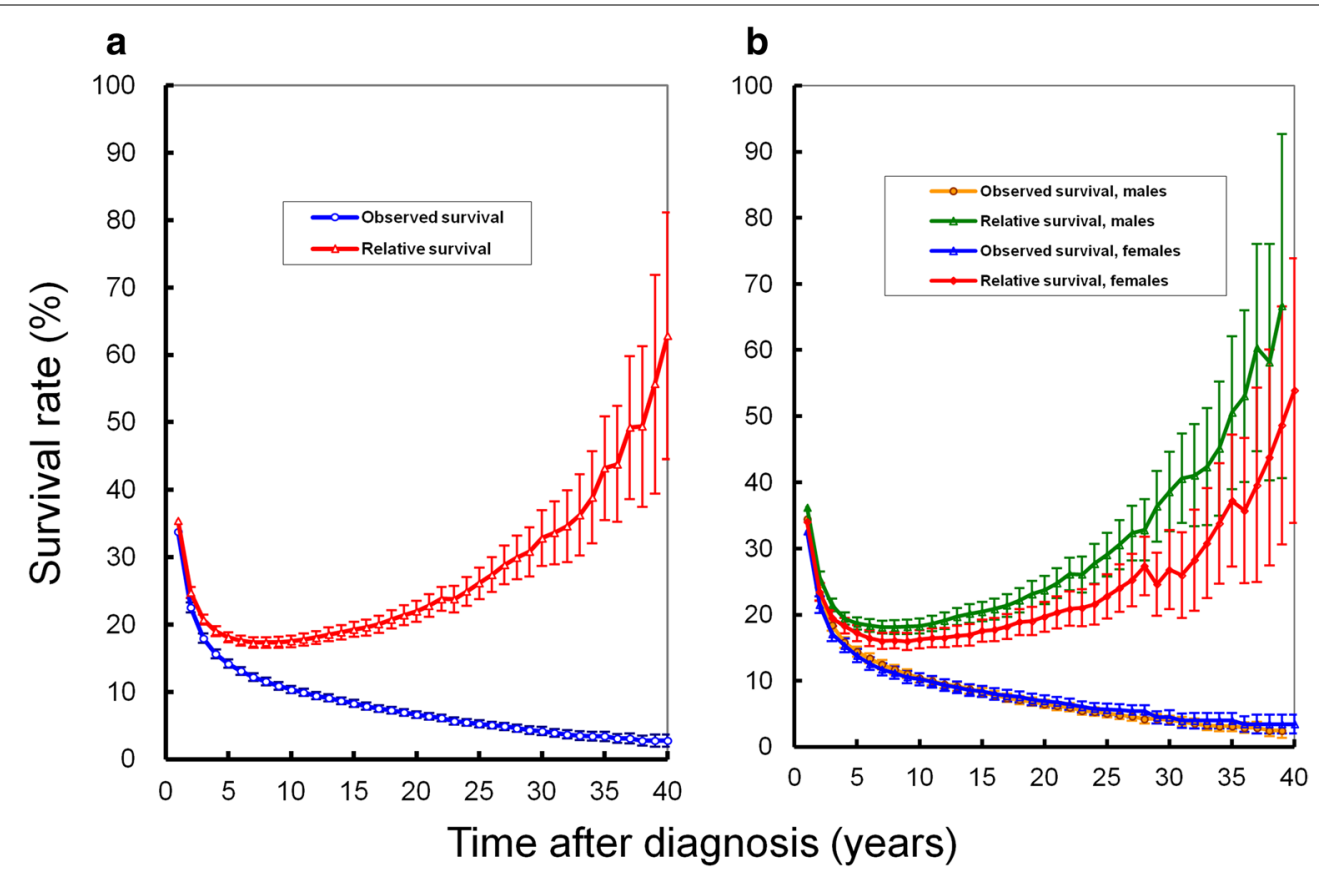

Fig. 1 Trends in observed survival rate and relative survival rate of gastric cancer patients in Qidong, China between 1972 and 2011. a Observed survival and relative survival rates of all patients. $\mathbf{b}$ Observed survival and relative survival rates for males and females 
the age group of $75+$ experienced the worst prognosis. For males, the highest 5 - and 10-year observed survival rates were seen in the age group of 35-44; the highest 5and 10-year relative survival rates were seen in the age group of 15-34. For females, the highest 5-year observed survival rate was seen in the age group of 35-44, but the highest 10 -year observed survival rate was seen in the age group of 45-54; the highest 5- and 10-year relative survival rates were seen in the age group of 35-44 (Table 1).

\section{Survival rate by period}

Table 2 shows that the relative survival rates of gastric cancer patients gradually increased over the past 40 years. The 1-year relative survival rate was $34.24 \%$ in 1972 and $45.15 \%$ in $2008-2011$. The 5 -year relative survival rate was $14.24 \%$ in 1972 and $26.67 \%$ in $2003-2007$. The 10-year relative survival rate increased from $11.10 \%$ in 1972 to $17.99 \%$ in $1998-2002$.

\section{Discussion}

Our results show an increasing trend in the survival rate of gastric cancer patients in Qidong over the past
40 years, which may be a reflection of improvements in cancer care services and cancer prevention.

The observed survival rate generally decreases over time within a group of patients, but the relative survival rate does not always do so. Our data show that the 1-9year relative survival rates decreased with increasing survival duration, whereas the 10-40-year relative survival rates increased with survival duration, indicating that the patients with gastric cancer who survived more than 10 years had a lower probability of death due to other causes than the general population did.

Our findings indicate that female gastric cancer patients experienced a worse prognosis than did males. This outcome is similar to survival data from Japan [16] and Korea [17]. Males aged 15-34 and females aged 35-44 experienced the highest relative survival rates, which may reflect disparities between sexes and ages. In Qidong, the proportion of patients with gastric cancer who underwent surgical resection was higher in the younger-age groups than in the older-age groups. Young males have a generally healthy status, which may explain their better outcome than elder males in

Table 1 The 5- and 10-year observed survival and relative survival rates for gastric cancer patients in different age groups in Qidong, China between 1972 and 2011

\begin{tabular}{|c|c|c|c|c|c|c|c|c|c|c|c|c|}
\hline \multirow[t]{3}{*}{ Age group } & \multicolumn{6}{|c|}{ Observed survival rate (\%) } & \multicolumn{6}{|c|}{ Relative survival rate (\%) } \\
\hline & \multicolumn{3}{|l|}{ 5-year } & \multicolumn{3}{|c|}{ 10-year } & \multicolumn{3}{|l|}{ 5-year } & \multicolumn{3}{|c|}{ 10-year } \\
\hline & Males & Females & Total & Males & Females & Total & Males & Females & Total & Males & Females & Total \\
\hline $15-34$ & 20.05 & 21.82 & 15.89 & 20.30 & 22.01 & 14.09 & 23.60 & 16.42 & 16.13 & 23.71 & 16.94 & 16.49 \\
\hline $35-44$ & 29.12 & 25.59 & 18.61 & 29.92 & 16.12 & 19.17 & 21.32 & 24.43 & 21.77 & 21.58 & 26.01 & 22.83 \\
\hline $45-54$ & 23.37 & 22.94 & 18.13 & 24.51 & 23.87 & 19.22 & 22.12 & 18.91 & 18.63 & 22.67 & 21.21 & 20.50 \\
\hline $55-64$ & 17.28 & 17.25 & 13.59 & 19.24 & 18.89 & 15.71 & 17.17 & 12.18 & 12.61 & 18.14 & 16.09 & 15.97 \\
\hline $65-74$ & 10.89 & 11.90 & 9.31 & 14.36 & 15.14 & 15.63 & 14.11 & 7.38 & 7.99 & 16.68 & 16.08 & 15.88 \\
\hline $75+$ & 6.32 & 5.81 & 2.86 & 14.80 & 12.27 & 11.99 & 5.21 & 3.05 & 2.94 & 9.90 & 21.52 & 15.73 \\
\hline Total & 14.40 & 14.18 & 10.22 & 18.67 & 18.13 & 16.28 & 13.80 & 10.42 & 10.35 & 17.21 & 18.21 & 17.50 \\
\hline
\end{tabular}

Table 2 Relative survival rate of gastric cancer patients by periods in Qidong, China between 1972 and 2011

\begin{tabular}{|c|c|c|c|c|c|c|c|}
\hline \multirow[t]{2}{*}{ Period } & \multicolumn{7}{|c|}{ Relative survival rate (\%) } \\
\hline & 1-year & 3-year & 5-year & 10-year & 15-year & 20-year & 30-year \\
\hline 1972 & 34.24 & 16.77 & 14.24 & 11.10 & 9.55 & 5.63 & 7.95 \\
\hline 1973-1977 & 33.71 & 14.89 & 11.79 & 9.10 & 8.88 & 9.10 & 15.49 \\
\hline 1978-1982 & 31.75 & 16.92 & 13.53 & 11.91 & 11.80 & 12.55 & 15.07 \\
\hline 1983-1987 & 32.07 & 17.89 & 14.47 & 13.12 & 15.04 & 18.64 & NA \\
\hline 1988-1992 & 32.85 & 20.25 & 18.09 & 18.91 & 21.90 & 25.31 & NA \\
\hline 1993-1997 & 30.57 & 18.43 & 16.92 & 17.73 & 20.25 & NA & NA \\
\hline 1998-2002 & 35.66 & 20.20 & 18.01 & 17.99 & NA & NA & NA \\
\hline 2003-2007 & 42.00 & 28.26 & 26.67 & NA & NA & NA & NA \\
\hline 2008-2011 & 45.15 & 31.08 & NA & NA & NA & NA & NA \\
\hline
\end{tabular}

NA not available 
the present study. However, the reason why middle-age female patients had a significantly better prognosis than females in other age groups is unclear.

The prognosis of gastric cancer in Qidong is not very good compared with that in developed countries $[8,18]$ and in developed areas of China [19]. However, when the cumulative 40-year data were divided into nine periods using the data from 1972 as a baseline for comparison, we found that the 1-, 5-, 10-, and 15-year relative survival rates were getting better with the calender periods, indicating that the prognosis has been improving with the expansion of health services and the economic development in this area.

At present, there are few available data on long-term survival rates of gastric cancer patients from studies similar to our population-based series (Table 3). In China, the 5 -year survival rate of gastric cancer patients in Qidong was lower than the rates in urban areas such as Beijing [19], Shanghai [20], and Tianjin [21] and was close to the rates in rural areas such as Changle, in Fujian Province
[22], and Cixian, in Hebei Province [23]. These findings indicate that there is a substantial gap in gastric cancer patient survival between rural and urban areas in China. Survival rates of gastric cancer patients are far better in Japan [16], South Korea [17], and Germany [24] than in China [6]. In the United States, the survival was better in 2003-2009 than in 1975-1977, indicating improvement over the past few decades [18]. Global disparities in gastric cancer patient survival exist. In the recent Concord II study, for patients diagnosed during 2005-2009, the agestandardized 5-year net survival rate of gastric cancer patients was very high in South Korea (58\%), Japan (54\%), and Mauritius (41\%), and the 5-year survival rate varied widely between registries in Africa, Asia, and Central and South America [25]. In Japan, a report showed that the 5-year survival rate of gastric cancer patients reached $62.1 \%$ during the 1990s [16], whereas in a recent report from Estonia, the gastric cancer patient survival rate in 1995-2006 was 20\% in males and 23\% in females [26]. Furthermore, in certain undeveloped countries, such as

Table 3 Comparison of 5-year survival rate of gastric cancer patients between Qidong and different countries and areas

\begin{tabular}{|c|c|c|c|c|}
\hline Area & Sex & Observed survival rate (\%) & Relative survival rate (\%) & Period \\
\hline \multirow[t]{3}{*}{ China [6] } & Males + females & NA & 27.40 & $2003-2005$ \\
\hline & Males & NA & 27.90 & $2003-2005$ \\
\hline & Females & NA & 26.50 & $2003-2005$ \\
\hline Gambia [7] & Males + females & NA & 3.00 & 1993-1997 \\
\hline \multirow[t]{4}{*}{ Korea [17] } & Males & NA & 43.80 & 1993-1997 \\
\hline & Females & NA & 43.00 & \\
\hline & Males & NA & 50.30 & 1998-2002 \\
\hline & Females & NA & 48.70 & \\
\hline \multirow[t]{4}{*}{ USA [18] } & Males & NA & 14.40 & 1975-1977 \\
\hline & Females & NA & 16.60 & \\
\hline & Males & NA & 26.70 & 2003-2009 \\
\hline & Females & NA & 32.00 & \\
\hline \multirow[t]{4}{*}{ Beijing, China [19] } & Males & 10.40 & NA & 1982-1983 \\
\hline & Females & 11.30 & NA & \\
\hline & Males & 17.60 & NA & 1987-1988 \\
\hline & Females & 19.50 & NA & \\
\hline Shanghai, China [20] & Males + females & 25.87 & 35.24 & 2002-2006 \\
\hline \multirow[t]{2}{*}{ Tianjin, China [21] } & Males & 13.00 & 23.97 & 1981-1985 \\
\hline & Females & 13.00 & 15.70 & \\
\hline \multirow[t]{2}{*}{ Changle, China [22] } & Males & 13.37 & NA & 1989-1998 \\
\hline & Females & 5.58 & NA & \\
\hline Cixian, China [23] & Males + females & 15.69 & 17.35 & 2000-2002 \\
\hline Saarland, Germany [24] & Males + females & NA & 35.10 & 2000-2002 \\
\hline Japan [16] & Males + females & 54.40 & 62.10 & 1993-1996 \\
\hline \multirow[t]{2}{*}{ Estonia [26] } & Males & NA & 20.00 & 1995-2006 \\
\hline & Females & NA & 23.00 & \\
\hline Kampala, Uganda [27] & Males + females & NA & 0.00 & 1993-1997 \\
\hline
\end{tabular}

NA not available 
the African countries Gambia [7] and Uganda [27], the 3 -year survival rate of gastric cancer patients was only $8.5 \%$, and the 5 -year survival rate was zero.

Survival of gastric cancer patients is influenced by many factors, including the clinical stage at diagnosis, the pathologic subtype of the tumor, the biological behavior of tumor cells, and the degree of tumor cell differentiation. Ideally, these factors should be considered while analyzing and comparing survival rates from different settings or areas. However, these data are not easy to obtain by a population-based cancer registry.

The results from our cancer registry provide a longterm assessment for survival of gastric cancer patients in China and provide a platform for a comprehensive survey of prognostic factors as well as health care services for gastric cancer patients in rural areas.

\section{Authors' contributions}

All authors participated in data collection. YSC carried out the data analyses and interpretation under supervision of JGC. YSC wrote the first draft of the manuscript. JGC checked and corrected the draft. All authors read and approved the final manuscript.

\section{Author details}

${ }^{1}$ Qidong Liver Cancer Institute, Qidong People's Hospital, Qidong, Jiangsu 226200, P.R. China. ${ }^{2}$ Department of Epidemiology, Nantong University Tumor Hospital/Institute, Nantong, Jiangsu 226361, P.R. China.

\section{Acknowledgements}

We thank the staff from cancer registries at 12 towns for patient selection and follow-up. We thank Dr. Thomas W. Kensler, a professor at both Johns Hopkins University and the University of Pittsburgh, for his useful comments and language editing. This work was supported partially by the National Central Cancer Registries of China (the Tumor Follow-up Registration Programs MF2008293, 2009-193, and 2010-90) and by the National Science and Technology Mega-Projects of China (2012ZX100020009-018 and 2012ZX10002-008).

\section{Competing interests}

The authors declare that they have no competing interests.

Received: 13 May 2015 Accepted: 11 August 2015

Published online: 19 October 2015

\section{References}

1. Ferlay J, Soerjomataram I, Ervik M, Dikshit R, Eser S, Mathers C, et al. GLOBOCAN 2012 v1.0, Cancer Incidence and Mortality Worldwide: IARC CancerBase No. 11. Lyon, France: International Agency for Research on Cancer. 2013. http://www.globocan.iarc.fr. Accessed 12 May 2015.

2. Varghese C, Carlos MC, Shin HR. Cancer burden and control in the Western pacific region: challenges and opportunities. Ann Glob Health. 2014;80(5):358-69.

3. Chen WQ, Zheng RS, Zhang SW, Zhao P, Li GL, Wu LY, et al. The incidences and mortalities of major cancers in China, 2009. Chin J Cancer. 2013;32(3):106-12.

4. Chen JG. Cancer in Qidong, China (1972-2011). Beijing: Mil Med Sci Press; 2013 (in Chinese)
5. Park JY, von Karsa L, Herrero R. Prevention strategies for gastric cancer: a global perspective. Clin Endosc. 2014;47(6):478-89.

6. Zeng HM, Zeng RS, Guo YM, Zhang S, Zou X, Wang N, et al. Cancer survival in China, 2003-2005: a population-based study. Int J Cancer. 2015;136(8):1921-30.

7. Sankaranarayanan R, Swaminathan R. Cancer survival in Africa, Asia, the Caribbean and Central America. IARC Sci Publ No. 162. Lyon: IARC; 2011

8. De Angelis R, Sant M, Coleman MP, Francisci S, Baili P, Pierannunzio D, et al. Cancer survival in Europe 1999-2007 by country and age: results of EUROCARE-5: a population-based study. Lancet Oncol. 2014;15:23-34.

9. Chen JG, Zhu J, Parkin DM, Zhang YH, Lu JH, Zhu YR, et al. Trends in the incidence of cancer in Qidong, China, 1978-2002. Int J Cancer. 2006;119(6):1447-54.

10. Zhao $P$, Chen WQ, Kong LZ. Cancer incidence and mortality in China (2003-2007). Beijing: Mil Med Sci Press; 2012 (in Chinese).

11. Parkin DM, Whelan SL, Ferlay J, Raymond L, Young J. Cancer incidence in five continents, Vol VII, IARC Sci Pub No. 143. Lyon: IARC; 1997.

12. Parkin DM, Whelan SL, Ferlay J, Storm H. Cancer incidence in five continents Vol. VIII, IARC Sci Pub No. 155. Lyon: IARC; 2002.

13. Finnish Cancer Registry. SURV3: windows software for relative survival analysis. http://www.cancerregistry.fi/surv3. Accessed on 1 Sept 2010.

14. Parkin DM, Hakulinen T. Chapter 12. Analysis of survival. In: Jensen OM Parkin DM, MacLennan R, editors. Cancer registration: principles and methods. IARC Sci Pub No.95. Lyon: IARC; 1991. p. 159-76.

15. Chen JG, Li WG, Shen ZC, Yao HY, Zhang BC, Zhu YR. Population-based cancer survival in Qidong, China. In: Sankaranarayanan R, Black R, Parkin DM, editors. Cancer survival in developing countries. IARC Sci Pub No. 145. Lyon: IARC; 1998. p. 27-35.

16. Tsukuma H, Ajiki W, loka A, Oshima A. Research Group of PopulationBased Cancer Registries of Japan. Survival of cancer patients diagnosed between 1993 and 1996: a collaborative study of population-based cancer registries in Japan. Jpn J Clin Oncol. 2006;36(9):602-7.

17. Jung KW, Yim SH, Kong HJ, Hwang SY, Won YJ, Lee JK, Shin HR. Cancer survival in Korea 1993-2002: a population-based study. J Korean Med Sci. 2007;22(Suppl):5-10.

18. Howlader N, Noone AM, Krapcho M. SEER Cancer Statistics Review, 1975-2010, National Cancer Institute. Bethesda, MD. http://www.seer. cancer.gov/csr/1975_2010/, based on November 2012 SEER data submission, posted to the SEER web site (2013). Accessed on 12 May 2014.

19. Wang QJ, Zhu WX, Li L, Xing XM. Cancer survival in urban Beijing. Chin Cancer. 2001;10(5):263-4 (in Chinese).

20. Li XP, Cao GW, Sun Q, Yang C, Yan B, Zhang MY, et al. Cancer incidence and patient survival rates among the residents in the Pudong New Area of Shanghai between 2002 and 2006. Chin J Cancer. 2013;32(9):512-9.

21. Wang QS, Ling XP, Li RT, Wang JF, Dong SF, Song N, et al. An analysis of relative survival rate in patients with malignancy in Tianjin. Chin Cancer. 2001;10(5):276-7 (in Chinese).

22. Xiao JR, Chen JS, Zhou Y, Chen LC, Wu JP. Survival analysis of 10409 cases with malignant cancers during 1989 to 1998 in Changle City. Chin J Prev Cont Chron Non-Commun Dis. 2005;13(5):225-7 (in Chinese).

23. He YT, Chen Y, Xu H, Song GH, Tian G, Chen C, Ji HX. Survival rate among cancer patients in Cixian county, 2000-2002. Chin J Public Health. 2011;27(9):1107-10 (in Chinese)

24. Brenner $\mathrm{H}$, Stegmaier $\mathrm{C}$, Ziegler H. Long-term survival of cancer patients in Germany achieved by the beginning of the third millennium. Ann Oncol. 2005;16(6):981-6.

25. Allemani C, Weir HK, Carreira H, Harewood R, Spika D, Wang XS, et al. Global surveillance of cancer survival 1995-2009: analysis of individual data for 25,676,887 patients from 279 population-based registries in 67 countries (CONCORD-2). Lancet. 2015:385(9972):977-1010.

26. Innos K, Padrik P, Valvere $V$, Aareleid T. Sex differences in cancer survival in Estonia: a population-based study. BMC Cancer. 2015;15:72.

27. Gondos A, Brenner H, Wabinga H, Parkin DM. Cancer survival in Kampala Uganda. Br J Cancer. 2005;92(9):1808-12. 